\title{
Publication Productivity of IS Researchers in the Pacific Asia Region: An Analysis of DSS and I\&M Journals (2003-2007)
}

\author{
Shin-Yuan Hung \\ Department of Information Management \\ National Chung Cheng University, Chia-Yi, Taiwan \\ syhung@mis.ccu.edu.tw \\ Wei-Hsi Hung \\ Department of Information Management \\ National Chung Cheng University, Chia-Yi, Taiwan \\ fhung@mis.ccu.edu.tw \\ Tsan-Ching Kang \\ Department of Information Management \\ National Chung Cheng University, Chia-Yi, Taiwan \\ tc.kang@gmail.com \\ King-Zoo Tang \\ Department of Information Management \\ National Chung Cheng University, Chia-Yi, Taiwan \\ kingzoo.tang@gmail.com
}

\begin{abstract}
This paper reports on the productivity of Pacific Asia scholars and academic institutions in the period 2003 to 2007 in two information systems journals: Decision Support Systems (DSS) and Information and Management (I\&M). We used the Web of Science database to track the publication records of the scholars and institutions. The results indicated that the Pacific Asia researchers provided notable contributions to these two journals and seem to treat them as their preferred publication outlets. Furthermore, the leading institutions in the Pacific Asia region show similar productivity to the leading institutions in North and South America in these two journals. The findings from this research shed more light on the productivity of Pacific Asia scholars.
\end{abstract}

Keywords: Information systems research, Pacific Asia scholars, Research productivity 


\section{Introduction}

As the economy of Pacific Asia has grown faster than other regions in the last few decades, the countries in the region have also placed more emphasis on higher education, which has resulted in an enhancement of research output in both quantity and quality. Therefore, it is of interest to know how the research environment has changed and how information systems researchers in the region have performed recently.

In an effort toward this end, Communications of the Association for Information Systems (CAIS) published a special issue in 2007 to look at the IS academic discipline offered by universities in different countries including Australia (Gable, 2007b), Hong Kong (Chau and Kuan, 2007), Korea (Lee and Yoo, 2007), New Zealand (Lehmann and Huff, 2007), Singapore (Tan and Chan, 2007), and Taiwan (Lee and Liang, 2007). The results showed that the Pacific Asia region is playing an important role in the advancement of the knowledge of the international IS society. In a previous issue of Pacific Asia Journal of the Association for Information Systems (PAJAIS), Lin and Gregor (2009) examined the publication productivity of IS researchers in six elite IS journals: the "Basket of Six" proposed by the Association for Information Systems. The results showed that authors in the region have been under-represented in the sampled journals.

In addition to the Basket of Six journals, however, authors in the region also publish in two journals that are highly ranked: Decision Support Systems (DSS) and Information \& Management (I\&M). Therefore, it seems reasonable to examine the productivity of Pacific Asia authors in these two journals as well. In fact, Palvia, Pinjani, and Sibley (2007) found in a recent survey that eight Pacific Asia universities appeared in the top 24 universities based on the number of papers published in I\&M in the period 1992 to 2005.
Twelve Pacific Asia authors were ranked in the top 33 in the same period, which is higher than $30 \%$ of the prolific authors.

The purpose of this paper is to examine the productivity of Pacific Asia scholars in DSS and I\&M in the period from 2003 to 2007 to supplement the findings of Lin and Gregor (2009) in order to provide a more complete profile of research productivity in this region. The main reasons for selecting these two journals were because of their long history in publishing IS research papers and their relatively high impact factors. They have also been included in the evaluation of researcher productivity and journal quality in many previous studies (e.g., Hardgrave and Walstrom, 1997; Holsapple et al., 1993; Huang and Hsu, 2005; Mylonopolous and Theoharakis, 2001; Walstrom et al., 1995). Therefore, the productivity information of these two journals is useful in providing a better profile of Pacific Asia research.

\section{IS Publication Productivity and Journal Selection}

\section{IS publication productivity}

Two approaches are commonly used for reporting authors' and institutions' productivities (Im et al., 1998; Lowry et al., 2007). One is the normal count which means that authors receive a full score for any published paper regardless of their participation. The other is the adjusted count. Authors' scores are calculated on the value of 1 divided by the number of authors in the article (Chua et al., 2003; Lin and Gregor, 2009). When counting the institutions' productivity, the calculation approach is similar. The citation score for a particular university is aggregated by the scores of the authors who are associated with the university (Lowry et al., 2007).

In addition to the calculation method, the selection of journals and analysis period is critically associated with the result of publication productivity. Recently, Lin and 
Gregor (2009) selected the Basket of Six journals as targets to demonstrate publication productivity in the Pacific Asia region. The Basket of Six journals - including European Journal of Information Systems (EJIS), Information Systems Journal (ISJ), Information Systems Research (ISR), Journal of the Association for Information Systems (JAIS), Journal of Management Information Systems (JMIS), and Management Information Systems Quarterly (MISQ) - are recommended by Association for Information Systems (AIS) as premier journals. As reported in the study, papers from the Pacific Asia region are under-represented in these journals. A possible reason is that these journals were not the main publishing outlets chosen by researchers in the Pacific Asia region. Therefore, identifying journals that have published more papers from authors in the region can provide a more complete profile of research productivity in the region.

\section{Journal Selection Criteria}

Two major criteria were used to justify the selection of these two journals. First, these two journals are among the earlier journals in information systems and they have significantly contributed to the development of the subject in general. I\&M started its publication in 1977 and DSS started it publication in 1985. Both have stayed as major publication outlets for over 20 years and many scholars have built their careers on them.

The second criterion was the popularity and quality perceived in the IS field. Although they are not generally ranked among the top three journals in the area, they are well-received by many schools as respectable journals. They have consistently enjoyed high respect over time and are ranked among the top ten, regardless of the rankings approach used (e.g., Lowry et al., 2004, Peffers and Tang, 2003). DSS was the top decision science journal and top economic journal in Lowry et al. (2004). It is oriented toward design science research in the area and has published a large portion of design science papers in information systems. Since 2000, it has also expanded to electronic commerce and related areas publishing many highly cited papers.

I\&M is also regarded as a highly respectable academic journal in IS research (Lowry et al., 2004; Peffers and Tang, 2003). It started publication in 1977, the same year that MIS Quarterly was published, and has remained active for more than 30 years with a broad international readership and a significant diversity amongst its authors, reviewers, and research topics. Therefore, analyzing the author profile in $1 \& M$ also enhances our understanding of IS research.

Both journals are popular in many surveybased journal rankings. For instance, without considering MIS Quarterly, Information Systems Research and Journal of MIS, DSS and $I \& M$ are ranked the first and second pure MIS journals (Rainer and Miller, 2005), the third and first high-quality is journals recognized by scholars (Peffers and Tang, 2003), the second and fourth globally read journals in pure IS (Lowry et al., 2004), and the fourth and sixth high-quality IS journals respectively (Lowry et al., 2004). Moreover, the impact factors of DSS and I\&M have been relatively high over the past five years. The 5Year Impact factors are 1.725 for DSS and 2.756 for I\&M in 2007. Therefore, it seems logical that scholars in the Pacific Asia region have interests in publishing their research findings in these journals.

\section{Methods}

In order to compare our research with existing studies, we used both normal and adjusted counts to assess research productivity. Any author whose name appeared on an article was given one mark when the normal count rule was applied, and was given an equally shared mark with other author(s) when counting the adjusted contribution. 
All articles published in the period 2003 to 2007 in DSS and I\&M were included in our initial analysis, a total of 911 . We then used the article category in the Web of Science to remove editorial and errata items, which resulted in our total sample size for further analysis of 883 . Table 1 shows the sample distribution information. As we can see in the table, DSS published more papers than I\&M in the survey period (545 versus 338) and published more papers than any other IS journals in the same period.

\begin{tabular}{|c|c|c|c|}
\hline Table 1 - Selection Details for DSS and I\&M Journals in 2003-2007 \\
\hline \multirow{2}{*}{ Journal } & \multicolumn{2}{|c|}{ Article Type } & \multirow{2}{*}{ Total Articles } \\
\cline { 2 - 3 } & Research & Editorial/Errata & \\
\hline$D S S$ & 545 & 24 & 569 \\
\hline$I \& M$ & 338 & 4 & 342 \\
\hline Total Articles & 883 & 28 & 911 \\
\hline
\end{tabular}

We then retrieved the author affiliation information from the Web of Science and classified it into one of the three regions based on the AIS definition (AIS Region, 2008): Region 1 - North and South America areas; Region 2 - Europe and Africa areas; and Region 3 - Asia and Oceania areas. Each author was assigned to only one region. Most researchers had not moved from one region to another over the time period of the analysis. Those who had moved were assigned to the region with which they were associated as shown on the most recent publication, except for a few cases where the author may have spent a short period visiting another institution (e.g., visiting an European school during a sabbatical year). In this case, the author was classified according to his/her main affiliation.

For analyzing leading institutions, the score was based totally on the author's affiliation information as shown on the article. Most researchers were affiliated with only one institution. For authors showing two affiliations in one paper, the credit is split between them. In order to enhance the accuracy of our data coding, two of the authors followed the rules and procedures described above to calculate data separately. Their results were then compared. Any inconsistent coding was further examined by the third and fourth co-authors until a consensus was reached.

\section{Findings and Discussions}

\section{Leading Researchers' Productivity across Regions}

The collected data was used to analyze author and institutional productivity. First, we analyzed the distribution of authors in the three regions. Table 2 shows the result of adjusted counts for each of the two journals in the period 2003 to 2007.

\begin{tabular}{|l|c|c|c|c|c|}
\hline \multicolumn{6}{|l|}{ Table 2 - Summary of Publication by Region in 2003-2007 } \\
\hline \multicolumn{1}{|c|}{} & $\begin{array}{c}\text { Region 1 } \\
\text { North and South America }\end{array}$ & $\begin{array}{c}\text { Region 2 } \\
\text { Europe and Africa }\end{array}$ & $\begin{array}{c}\text { Region 3 } \\
\text { Pacific Asia }\end{array}$ & Total \\
\hline \multirow{3}{*}{$\begin{array}{l}\text { Total Publication: } \\
\text { Adjusted Counts }\end{array}$} & $D S S$ & 306.07 & 94.66 & 144.28 & 545 \\
& $(56.16 \%)$ & $(17.37 \%)$ & $(26.47 \%)$ & $(100 \%)$ \\
\cline { 2 - 6 } & $1 \& M$ & 176.97 & 59.43 & 101.61 & 338 \\
$(12.36 \%)$ & $(17.58 \%)$ & $(30.06 \%)$ & $(100 \%)$ \\
\hline
\end{tabular}


The results show that researchers in Region 1 contributed more than half of the total papers published in these two journals, followed by Region 3 authors and Region 2 authors.

Regarding an individual author's contribution, 97 researchers have adjusted counts of over 1.0 (see Appendix 1). We may call them leading researchers. They have contributed 157.87 of the 883 papers, that is, $17.88 \%$ of the total publications. This also shows that these two journals cover a pretty broad authorship with no obvious dominating person or group. Table 3 presents the distribution of the 97 leading researchers in three regions.

\begin{tabular}{|}
\begin{tabular}{|c|c|c|c|c|}
\hline $\begin{array}{c}\text { Table 3- Distribution of Leading Researchers who published in DSS and I\&M } \\
\text { in 2003-2007 }\end{array}$ & $\begin{array}{c}\text { Region 2 } \\
\text { Europe and Africa }\end{array}$ & $\begin{array}{c}\text { Region 3 } \\
\text { Pacific Asia }\end{array}$ & Total \\
\hline & North and South America & 7.95 & 56.10 & 157.87 \\
& 93.82 & $(5.01 \%)$ & $(35.58 \%)$ & $(100 \%)$ \\
\hline Total Publication: & $(59.41 \%)$ & 15 & 104 & 346 \\
Adjusted Counts & 227 & $(4.33 \%)$ & $(30.06 \%)$ & $(100 \%)$ \\
\hline Total Publication: & $(65.61 \%)$ & 5 & 31 & 97 \\
Normal Counts & 61 & $(5.15 \%)$ & $(31.96 \%)$ & $(100 \%)$ \\
\hline Number of Leading & $(62.89 \%)$ & &
\end{tabular} Researchers &
\end{tabular}

As we can see in Table 3, the majority of the 97 researchers reside in Region 1, both journals showing a similar pattern. However, researchers in Region 2 are underrepresented in these two journals, for example, less than 20 of total publications and less than $6 \%$ of the leading researchers. There are 61 leading researchers (about 63\%) in Region 1 (North and South America), thirtyone (about 32\%) from Region 3 (Pacific Asia), but there are only 5 (less than 6\%) in Region 2 (Europe and Africa). For authors in Region 1 , only 3 are from Canada and the remaining 61 reside in the United States. This shows the outstanding contribution of scholars in the US toward IS development. Of the 5 leading scholars in Region 2, two each are based in the United Kingdom and Netherlands, and 1 from Belgium. The 31 authors in Region 3, 12 are from Taiwan, 8 from Hong Kong, 7 from Korea, 2 from Singapore, and 1 each from Australia and China.

The results indicate that although these two journals are non-Pacific-Asia based, the Pacific Asia researchers published almost one third of the papers in these two journals. For a comparison, the leading researchers in our list are quite different from those on the list of the Basket of Six journals (Lin and
Gregor, 2009), where the percentage in Pacific Asia is $3.56 \%$ by the adjusted count and $3.96 \%$ by the number of leading researchers.

\section{Leading Researchers within Region 3}

Table 4 shows the names and affiliations of the 31 leading Region 3 researchers who scored more than 1.0 in terms of adjusted count. The highest one scored 4.00. None of them scored in the range of 3.00 to 3.99 , but 11 researchers scored in the range of 2.00 to 2.99 , and 19 in the range of 1.00 to 1.99 .

The researchers are mainly from six regions/countries. Twelve of them are from Taiwan, which represents $38.71 \%$ of the 31 leading researchers; 8 are from Hong Kong $(25.81 \%), 7$ are from Korea $(22.58 \%) ; 2$ are from Singapore $(6.45 \%)$; and 1 each from Australia and China. Interestingly, the only researcher from China is ranked the highest.

Table 5 shows the distribution of papers published by the 31 leading researchers in the two journals. In terms of the total number of normal count, these researchers have published consistently in the period 2003 to 2006 but show a small drop in 2007. 


\begin{tabular}{|c|c|c|c|}
\hline Rank & Researcher & University $^{a}$ & $\begin{array}{l}\text { Total Publication: } \\
\text { Adjusted Counts }\end{array}$ \\
\hline 1 & Zhuge, Hai & Chinese Academy of Sciences (CN) & 4.00 \\
\hline 2 & Chiu, Chao-Min & National Central University (TW) & 2.83 \\
\hline 2 & Teo, Thompson S.H. & National University of Singapore (SG) & 2.83 \\
\hline 4 & Ngai, E.W.T. & Hong Kong Polytechnic University (HK) & 2.75 \\
\hline 5 & Wu, Jen-Her & National Sun Yat-Sen University (TW) & 2.37 \\
\hline 6 & Bose, Indranil & University of Hong Kong (HK) & 2.17 \\
\hline 7 & Yang, Christopher C. & Chinese University of Hong Kong (HK) & 2.08 \\
\hline 8 & Choe, Jong-Min & Kyungpook National University (KR) & 2.00 \\
\hline 8 & Choi, Dae-Young & Yuhan College (KR) & 2.00 \\
\hline 8 & Huang, Ming-Hui & National Taiwan University (TW) & 2.00 \\
\hline 8 & Shih, Hung-Pin & Hsuan Chuang University (TW) & 2.00 \\
\hline 8 & Wu, Ing-Long & National Chung Cheng University (TW) & 2.00 \\
\hline 13 & Cheung, Waiman & Chinese University of Hong Kong (HK) & 1.92 \\
\hline 13 & Chen, Yen-Liang & National Central University (TW) & 1.83 \\
\hline 13 & Wang, Eric T.G. & National Central University (TW) & 1.83 \\
\hline 13 & Wang, Yi-Shun & National Changhua University of Education (TW) & 1.83 \\
\hline 17 & Love, Peter E.D. & Edith Cowan University (AU) & 1.53 \\
\hline 18 & Chan, Samuel W.K. & Chinese University of Hong Kong (HK) & 1.50 \\
\hline 18 & Kwon, Oh Byung & Kyunghee University (KR) & 1.50 \\
\hline 18 & Lee, Jae Kyu & $\begin{array}{l}\text { Korea Advanced Institute of Science and } \\
\text { Technology (KR) }\end{array}$ & 1.50 \\
\hline 18 & Yen, Benjamin P.C. & University of Hong Kong (HK) & 1.50 \\
\hline 22 & Hung, Shin-Yuan & National Chung Cheng University (TW) & 1.45 \\
\hline 23 & Han, Ingoo & $\begin{array}{l}\text { Korea Advanced Institute of Science and } \\
\text { Technology (KR) }\end{array}$ & 1.33 \\
\hline 24 & Hu, Ya-Han & National Central University (TW) & 1.25 \\
\hline 24 & Wang, Huaiqing & City University of Hong Kong (HK) & 1.25 \\
\hline 26 & Kim, Myoung Ho & $\begin{array}{l}\text { Korea Advanced Institute of Science and } \\
\text { Technology (KR) }\end{array}$ & 1.17 \\
\hline 26 & Lai, Vincent S. & Chinese University of Hong Kong (HK) & 1.17 \\
\hline 26 & Lee, Sangjae & Sejong University (KR) & 1.17 \\
\hline 26 & Pan, Shan L. & National University of Singapore (SG) & 1.17 \\
\hline 30 & Hsu, Meng-Hsiang & $\begin{array}{l}\text { National Kaohsiung First University of Science and } \\
\text { Technology (TW) }\end{array}$ & 1.08 \\
\hline 30 & Wei, Chih-Ping & National Tsing Hua University (TW) & 1.08 \\
\hline \multicolumn{4}{|c|}{${ }^{a}$ : AU: Australia, CN: China, HK: Hong Kong, KR: Korea, SG: Singapore, TW: Taiwan } \\
\hline
\end{tabular}


Table 5 -The 31 Leading Researchers in The Pacific Asia Region with Publication Productivity in DSS and I\&M in 2003-2007

\begin{tabular}{|c|c|c|c|c|c|}
\hline Year & 2003 & 2004 & 2005 & 2006 & 2007 \\
\hline DSS & $\begin{array}{l}\text { Choi, Dae-Young (1.00) } \\
\text { Zhuge, Hai (1.00) } \\
\text { Yang, Christopher C. (0.33) }\end{array}$ & $\begin{array}{l}\text { Hsu, Meng-Hsiang (0.75) } \\
\text { Yang, Christopher C. }(0.75) \\
\text { Chan, Samuel W.K. }(0.50) \\
\text { Chiu, Chao-Min }(0.50) \\
\text { Kim, Myoung Ho }(0.50) \\
\text { Kwon, Oh Byung }(0.50) \\
\text { Lee, Jae Kyu }(0.50) \\
\text { Wei, Chih-Ping }(0.50) \\
\text { Wu, Jen-Her }(0.20)\end{array}$ & $\begin{array}{l}\text { Lee, Jae Kyu (1.00) } \\
\text { Teo, Thompson S.H. (1.00) } \\
\text { Ngai, E.W.T.(0.50) } \\
\text { Cheung, Waiman (0.33) } \\
\text { Chen, Yen-Liang (0.25) } \\
\text { Hu, YH(0.25) }\end{array}$ & $\begin{array}{l}\text { Chen, Yen-Liang (1.33) } \\
\text { Wang, Eric T.G. (1.33) } \\
\text { Pan, Shan L. (1.17) } \\
\text { Chan, Samuel W.K. (1.00) } \\
\text { Cheung, Waiman (1.00) } \\
\text { Hu, Ya-Han (1.00) } \\
\text { Kwon, Oh Byung (1.00) } \\
\text { Zhuge, Hai(1.00) } \\
\text { Wang, Huaiqing (0.5) } \\
\text { Chiu, Chao-Min (0.33) } \\
\text { Hsu, Meng-Hsiang (0.33) } \\
\text { Teo, Thompson S.H. (0.33) } \\
\text { Wei, Chih-Ping (0.33) }\end{array}$ & $\begin{array}{l}\text { Ngai, E.W.T. (0.75) } \\
\text { Yang, Christopher C. (1.00) } \\
\text { Choi, Dae-Young (1.00) } \\
\text { Yen, Benjamin P.C. }(1.00) \\
\text { Hung, Shin-Yuan }(0.25) \\
\text { Wang, Huaiqing }(0.25) \\
\text { Kim, Myoung Ho }(0.67) \\
\text { Lai, Vincent S. }(0.33) \\
\text { Wei, Chih-Ping }(0.25)\end{array}$ \\
\hline I\&M & \begin{tabular}{|l} 
Zhuge, Hai(2.00) \\
Chiu, Chao-Min (1.00) \\
Choe, Jong-Min (1.00) \\
Han, Ingoo (1.00) \\
Huang, Ming-Hui (1.00) \\
Hung, Shin-Yuan (1.00) \\
Ngai, E.W.T.(1.00) \\
Wang, Yi-Shun (1.00) \\
Wu, Ing-Long (1.00) \\
Love, Peter E.D. (0.83) \\
Lee, Sangjae (0.50) \\
Wang, Eric T.G. (0.50) \\
Wu, Jen-Her(0.50) \\
Yen, Benjamin P.C. (0.50) \\
Chen, Yen-Liang (0.25)
\end{tabular} & $\begin{array}{l}\text { Shih, Hung-Pin (2.00) } \\
\text { Choe, Jong-Min }(1.00) \\
\text { Teo, Thompson S.H. }(1.00) \\
\text { Love, Peter E.D. }(0.50) \\
\text { Wang, Yi-Shun }(0.33) \\
\text { Wu, Jen-Her }(0.33) \\
\text { Hung, Shin-Yuan }(0.20)\end{array}$ & $\begin{array}{l}\text { Chiu, Chao-Min (1.00) } \\
\text { Huang, Ming-Hui }(1.00) \\
\text { Lai, Vincent S. }(0.83) \\
\text { Lee, Sangjae }(0.67) \\
\text { Teo, Thompson S.H. (0.50) } \\
\text { Wu, Jen-Her (0.50) } \\
\text { Bose, Indranil }(0.33) \\
\text { Cheung, Waiman }(0.33) \\
\text { Love, Peter E.D. }(0.20)\end{array}$ & \begin{tabular}{|l} 
Bose, Indranil $(1.00)$ \\
Wu, Ing-Long $(1.00)$ \\
Wang, Huaiqing $(0.50)$ \\
Wang, Yi-Shun $(0.50)$ \\
Wu, Jen-Her $(0.50)$
\end{tabular} & $\begin{array}{l}\text { Ngai, E.W.T.(0.50) } \\
\text { Wu, Jen-Her(0.33) } \\
\text { Cheung, Waiman (0.25) } \\
\text { Han, Ingoo }(0.33)\end{array}$ \\
\hline Adjusted Counts & 15.41 & 10.06 & 8.69 & 14.15 & 6.91 \\
\hline Normal Counts & 18.00 & 16.00 & 15.00 & 18.00 & 13.00 \\
\hline
\end{tabular}




\section{Leading Universities in Region 3}

Based on the total number of adjusted counts for each institution, the top 30 institutions are shown in Table 6, which includes 18, 1, and 11 institutions from Regions 1, 2, and 3, respectively. The University of Arizona is ranked top, followed by the Chinese University of Hong Kong. The only institution from Region 2 is Brunel University. Top ranked institutions in Region 3 are mainly from four regions/countries: Hong Kong (5), Taiwan (4), South Korea (1), and Singapore (1). This result shows that IS scholars in Taiwan and Hong Kong are the primary Region 3 contributors to these two journals in the period 2003-2007.

\section{Table 6 -The Leading 30 Institutions by Region in DSS and I\&M in 2003-2007}

Region 1: North and South America

\begin{tabular}{|c|c|c|}
\hline Rank & Institution $^{a}$ & $\begin{array}{l}\text { Total Publication: } \\
\text { Adjusted Counts }\end{array}$ \\
\hline 1 & University of Arizona (US) & 17.47 \\
\hline 2 & Pennsylvania State University (US) & 11.58 \\
\hline 3 & University of Florida (US) & 11.17 \\
\hline 4 & California State University (US) & 10.50 \\
\hline 5 & University of Wisconsin (US) & 10.33 \\
\hline 6 & University of Texas (US) & 9.32 \\
\hline 7 & State University of New York (US) & 9.30 \\
\hline 8 & University of South Florida (US) & 8.42 \\
\hline 9 & Arizona State University (US) & 8.17 \\
\hline 10 & Georgia State University (US) & 8.05 \\
\hline 11 & University of Michigan (US) & 7.17 \\
\hline 12 & University of Kentucky (US) & 6.83 \\
\hline 12 & University of North Carolina (US) & 6.83 \\
\hline 14 & University of Connecticut (US) & 6.75 \\
\hline 15 & University of Maryland (US) & 6.33 \\
\hline 16 & Texas Tech University (US) & 6.17 \\
\hline 17 & University of Massachusetts (US) & 5.67 \\
\hline 18 & University of Colorado (US) & 5.53 \\
\hline \multicolumn{3}{|c|}{ Region 2: Europe and Africa } \\
\hline Rank & Institution $^{a}$ & $\begin{array}{l}\text { Total Publication: } \\
\text { Adjusted Counts }\end{array}$ \\
\hline 1 & Brunel University (UK) & 6.87 \\
\hline \multicolumn{3}{|c|}{ Region 3: Pacific Asia } \\
\hline Rank & Institution $^{a}$ & $\begin{array}{l}\text { Total Counts } \\
\text { (adjusted) }\end{array}$ \\
\hline 1 & Chinese University of Hong Kong (HK) & 14.68 \\
\hline 2 & Korea Advanced Institute of Science and Technology (KR) & 13.92 \\
\hline 3 & National University of Singapore (SG) & 11.58 \\
\hline 4 & National Central University (TW) & 10.87 \\
\hline 5 & City University of Hong Kong (HK) & 10.34 \\
\hline 6 & National Sun Yat-Sen University (TW) & 8.89 \\
\hline 7 & National Chung Cheng University (TW) & 8.33 \\
\hline 8 & The University of Hong Kong (HK) & 7.00 \\
\hline 9 & Hong Kong Polytechnic University (HK) & 6.25 \\
\hline 10 & Hong Kong University of Science and Technology (HK) & 6.23 \\
\hline 11 & Chinese Academy of Sciences (CN) & 5.73 \\
\hline
\end{tabular}


Table 7 shows the top 30 institutions by their total adjusted counts. The Chinese University of Hong Kong is ranked top, followed by Korea Advanced Institute of Science and Technology and National University of Singapore. All of them scored higher than 10. Most institutions scored between 2 and 3 .
Those 30 institutions are mainly from six regions/countries: 14 from Taiwan; 5 from Hong Kong; 4 from Korea; 3 from Australia; and 2 each from China and Singapore. All five institutions from Hong Kong are ranked in the top 10. Surprisingly, no major Japanese universities are ranked in the top 30 .

\begin{tabular}{l} 
Table 7-The 30 Leading Institutions in the Pacific Asia region in DSS and I\&M \\
in 2003-2007 \\
\hline \multicolumn{1}{|c|}{ Institution ${ }^{\text {I }}$} \\
Rank
\end{tabular}

\section{Conclusion}

We have conducted a study to examine the productivity of Pacific Asia researchers in the journals of DSS and I\&M in order to have a better understanding of the IS research productivity in the Pacific Asia region. The results show that the Pacific Asia researchers provide notable contributions to the two journals. Almost one in every three leading authors who published papers in these two journals is from the Pacific Asia region. This finding is similar to the result of Palvia, Pinjani, and Sibley's (2007) and significantly different from the profile in the Basket of Six journals, 
where the percentage in Pacific Asia is $3.56 \%$ by the adjusted count and $3.96 \%$ by the number of leading researchers (Lin and Gregor, 2009). In this study, the percentage in Pacific Asia is $35.58 \%$ by the adjusted count and $31.96 \%$ by the number of leading researchers, respectively.

There are two possible reasons for explaining this discrepancy. First, Pacific Asia researchers prefer DSS and $I \& M$ as their publication outlets; second, the two journals are more friendly to Region 3 authors, such as having a stronger interest in research findings derived from data collected in the Pacific Asia region or research topics of interest to Region 3 authors. For understanding the research profile in Region 3 , therefore, DSS and I\&M provide valuable information.

\section{References}

AIS (Association for Information Systems) Region 2008. Retrieved $10^{\text {th }}$ September 2008 from http://home.aisnet.org/displaycommon .cfm?an $=1 \&$ subarticlenbr $=8$

Chau, P. Y. K., and Kuan, K. K. Y. (2007) "The Information Systems Academic Discipline in Hong Kong 2006", Communications of the Association for Information Systems 21, pp.49-60.

Chua, C., Cao, L., Cousins, K., and Straub., D. W. (2003) "Measuring ResearcherProduction in Information Systems", Journal of the Association for Information Systems 3 (4), pp.145215.

Eom, S. B. (1994) "Ranking Institutional Contributions to Decision Support Systems Research: A Citation Analysis", Data Base 25 (1), pp.35-42.

Eom, S. B., and Lee, S. M. (1993) "Leading Us Universities and Most Influential Contributors in Decision Support Systems Research (1971-1989)", Decision Support Systems 9 (3), pp.237-244.
Overall, our findings imply that the contribution from the Pacific Asia region to the IS community can be seen in past publications of DSS and I\&M, although neither journal is based in the Pacific Asia region. However, this study has several limitations. First, the study was based on two IS journals, which may not be a true representation of the overall profile of Pacific Asia authors. There are many other journals that publish articles from Pacific Asia, but are not included in the current study. Second, we only analyzed the papers published in the period 2003 to 2007. Some authors or institutions that may have published in these two journals outside the survey period are not shown in the findings. The rankings may change should the covered period change. Hence, our findings should be interpreted carefully when they are used.

Gable, G. G. (2007a) "The Information Systems Academic Discipline in Pacific Asia 2006: A Contextual Analysis", Communications of the Association for Information Systems 21, pp.1-22.

Gable, G. G. (2007b) "The Information Systems Academic Discipline in Australia 2006", Communications of the Association for Information Systems 21, pp.23-48.

Gable, G. G., and Smyth, R. W. (2007) "The State of the Is Academic Discipline in Pacific Asia 2006: Methodological Learnings", Communications of the Association for Information Systems 21, pp.166-194.

Gable, G. G., Lee, J.-N., Kwahk, K. Y., and Green, P. (2007) "Administrative Placement of the Information Systems Academic Discipline: A Comparative SWOT Analysis", Communications of the Association for Information Systems 21, pp.137-165.

Hardgrave, B. C., and Walstrom, K. A. (1997) "Forums for MIS Scholars", 
Communications of the ACM 40 (11) pp.119-124.

Holsapple, C. W., Johnson, L. E., Manakyan, H., and Tanner, J. (1993) "A Citation Analysis of Business Computing Research Journals", Information \&Management 25 (5), pp.231-244.

Huang, H. H., and Hsu, J. S. C. (2005) "An Evaluation of Publication Productivity in Information Systems: 1999 to 2003", Communications of the Association for Information Systems 15 (5), pp.555-564.

Im, K. S., Kim, K. Y., and Kim, J. S. (1998) "An Assessment of Individual and Institutional Research Productivity in MIS", Decision Line 29 (1), pp.8-12.

Lee, C. C., and Liang, T. P. (2007) "The Information Systems Academic Discipline in Taiwan - 2006: A Focus on Top-Tier Universities", Communications of the Association for Information Systems 21, pp.116136.

Lee, J. N., and Yoo, S. W. (2007) "The Information Systems Academic Discipline in Korea - 2006: A Focus on Leading Universities", Communications of the Association for Information Systems 21, pp.61-86.

Lehmann, H., and Huff, S. (2007) "The Information Systems Academic Discipline in New Zealand - 2006", Communications of the Association for Information Systems 21, pp.87-103.

Lin, A. C. H., and Gregor, S. (2009) "Publication Productivity in Information Systems 2003-2007: A Focus on the 'Basket of Six' and the Pacific Asia Region", Pacific Asia Journal of the Association for Information Systems 1 (1), pp.1-16.

Lowry, P. B., Karuga, G. G., and Richardson, V. J. (2007) "Assessing Leading Institutions, Faculty, and Articles in Premier Information Systems
Research Journals", Communications of the Association for Information Systems 20 (16), pp.142-203.

Lowry, P. B., Romans, D., and Curtis, A. (2004) "Global Journal Prestige and Supporting

Disciplines:

Scientometric Study of Information Systems Journals", Journal of the Association for Information Systems 5 (2), pp.29-77.

Mylonopolous, N. A., and Theoharakis, V. (2001) "On Site: Global Perceptions of IS Journals", Communications of the ACM 44 (9), pp.29-33.

Palvia, P., Pinjani, P., and Sibley, E. H. (2007) "A Profile of Information Systems Research Published in Information \& Management", Information \& Management 44 (1), pp.1-11.

Peffers, K., and YaTang, Y. T. (2003) "Identifying and Evaluating the Universe of Outlets for Information Systems Research: Ranking the Journals", Journal of Information Technology Theory and Application 5 (1), pp.63-84.

Rainer, R. K., and Miller, M. D. (2005) "Examining Differences across Journal Rankings", Communications of the ACM 48 (2), pp.91-94.

Tan, B. C. Y., and Chan, T. (2007) "The Information Systems Academic Discipline in Singapore 2006", Communications of the Association for Information Systems 21, pp.104115.

Walstrom, K. A., Hardgrave, B. C., and Wilson, R. L. (1995) "Forums for Management Information Systems Scholars", Communications of the ACM 38 (3), pp.93-106.

Whinston, A. B. (2009) "Aims \& Scope". Retrieved 6/3, 2009, from http://www.elsevier.com/wps/find/journ aldescription.cws home/505540/descr iption\#description 


\section{Appendix}

\section{Table 1 - The 97 Leading Researchers by Region in DSS and I\&M (ranked by adjusted counts)}

\begin{tabular}{|c|c|c|c|c|}
\hline Rank & Researcher & University $^{a}$ & $\begin{array}{l}\text { Adjusted } \\
\text { Count }\end{array}$ & $\begin{array}{c}\text { Normal } \\
\text { Count }\end{array}$ \\
\hline 1 & Chen, Hsinchun & University of Arizona (US) & 5.50 & 19 \\
\hline 2 & Pendharkar, Parag C. & Pennsylvania State University (US) & 4.00 & 5 \\
\hline 3 & Rao, H.R. & State University of New York at Buffalo (US) & 2.53 & 9 \\
\hline 4 & Amiri, Ali & Oklahoma State University (US) & 2.00 & 2 \\
\hline 4 & Kock, Ned & Texas A\&M International University (US) & 2.00 & 2 \\
\hline 4 & Lederer, Albert L. & University of Kentucky (US) & 2.00 & 4 \\
\hline 4 & Piramuthu, Selwyn & University of Florida (US) & 2.00 & 2 \\
\hline 4 & Zahedi, Fatemeh Mariam & University of Wisconsin Milwaukee (US) & 2.00 & 4 \\
\hline 9 & Jiang, James J. & University of Central Florida (US) & 1.87 & 7 \\
\hline 9 & Yen, David C. & Miami University (US) & 1.87 & 6 \\
\hline 11 & Fan, Weiguo & Virginia Polytechnic Institute and State University (US) & 1.83 & 6 \\
\hline 11 & Pathak, Praveen & University of Michigan (US) & 1.83 & 5 \\
\hline 13 & Paradice, David & Florida State University (US) & 1.75 & 3 \\
\hline 14 & Hevner, Alan R. & University of South Florida (US) & 1.67 & 5 \\
\hline 16 & Sherif, Karma & Texas Tech University (US) & 1.58 & 4 \\
\hline 17 & Bendoly, Elliot & Emory University (US) & 1.50 & 2 \\
\hline 17 & Brydon, Michael & Simon Fraser University (CA) & 1.50 & 2 \\
\hline 17 & Kearns, Grover S. & University of South Florida (US) & 1.50 & 2 \\
\hline 17 & Kim, YongSeog & Utah State University (US) & 1.50 & 2 \\
\hline 17 & Koehler, Gary J. & University of Florida (US) & 1.50 & 3 \\
\hline 17 & Nakayama, Makoto & DePaul University (US) & 1.50 & 2 \\
\hline 17 & Nevo, Dorit & York University (CA) & 1.50 & 3 \\
\hline 17 & Sundarraj, R.P. & University of Waterloo (CA) & 1.50 & 2 \\
\hline 17 & Taylor, Nolan J. & Indiana University (US) & 1.50 & 2 \\
\hline 17 & Torkzadeh, Gholamreza & University of Nevada (US) & 1.50 & 4 \\
\hline 17 & Umanath, Narayan S. & University of Cincinnati (US) & 1.50 & 2 \\
\hline 28 & Shao, Benjamin B.M. & Arizona State University (US) & 1.42 & 4 \\
\hline 28 & Zhang, Dongsong & University of Maryland (US) & 1.42 & 4 \\
\hline 30 & Kishore, Rajiv & State University of New York at Buffalo (US) & 1.37 & 5 \\
\hline 31 & Cheng, Hsing Kenneth & University of Florida (US) & 1.33 & 3 \\
\hline
\end{tabular}




\begin{tabular}{|c|c|c|c|c|}
\hline 31 & Dhillon, Gurpreet & Virginia Commonwealth University (US) & 1.33 & 2 \\
\hline 31 & Holsapple, Clyde W. & University of Kentucky (US) & 1.33 & 3 \\
\hline 31 & Kiang, Melody Y. & California State University (US) & 1.33 & 2 \\
\hline 31 & Sharda, Ramesh & Oklahoma State University (US) & 1.33 & 3 \\
\hline 31 & Song, Jaeki & Texas Tech University (US) & 1.33 & 3 \\
\hline 31 & Turetken, Ozgur & Ryerson University (US) & 1.33 & 3 \\
\hline 38 & Huang, Zhenyu & Central Michigan University (US) & 1.27 & 5 \\
\hline 39 & Hall, Dianne J. & Auburn University (US) & 1.25 & 3 \\
\hline 39 & Hu, Paul Jen-Hwa & University of Utah (US) & 1.25 & 4 \\
\hline 41 & Whinston, Andrew B. & University of Texas at Austin (US) & 1.20 & 4 \\
\hline 42 & Zhao, J. Leon & University of Arizona (US) & 1.17 & 4 \\
\hline 42 & Altinkemer, Kemal & Purdue University (US) & 1.17 & 3 \\
\hline 42 & Antony, Solomon & Murray State University (US) & 1.17 & 3 \\
\hline 42 & Gopal, Ram D. & University of Connecticut (US) & 1.17 & 4 \\
\hline 42 & Grover, Varun & Clemson University (US) & 1.17 & 3 \\
\hline 42 & Kumar, Akhil & Penn State University (US) & 1.17 & 3 \\
\hline 42 & Marsden, James R. & University of Connecticut (US) & 1.17 & 4 \\
\hline 42 & Mehta, Kumar & George Mason University (US) & 1.17 & 3 \\
\hline 42 & Mohan, Kannan & Baruch College (US) & 1.17 & 3 \\
\hline 42 & Ramesh, Balasubramaniam & Georgia State University (US) & 1.17 & 3 \\
\hline 42 & Santhanam, Radhika & University of Kentucky (US) & 1.17 & 3 \\
\hline 42 & Schuff, David & Temple University (US) & 1.17 & 3 \\
\hline 42 & Zhang, Han & Georgia Institute of Technology (US) & 1.17 & 3 \\
\hline 42 & Zhou, Lina & University of Maryland (US) & 1.17 & 3 \\
\hline 56 & Keil, Mark & Georgia State University (US) & 1.12 & 4 \\
\hline 57 & Lee, Sang M. & University of Nebraska (US) & 1.08 & 3 \\
\hline 57 & Lin, Zhangxi & Texas Tech University (US) & 1.08 & 3 \\
\hline 57 & Rai, Arun & Georgia State University (US) & 1.08 & 3 \\
\hline 60 & Sanders, G. Lawrence & State University of New York at Buffalo (US) & 1.03 & 3 \\
\hline 60 & Shin, Seung Kyoon & University of Rhode Island (US) & 1.03 & 3 \\
\hline \multicolumn{5}{|c|}{ Region 2: Europe and Africa } \\
\hline Rank & Researcher & University & $\begin{array}{c}\text { Adjusted } \\
\text { Count }\end{array}$ & $\begin{array}{c}\text { Normal } \\
\text { Count }\end{array}$ \\
\hline 1 & van der Heijden, Hans & University of Surrey (NL) & 2.50 & 3 \\
\hline 2 & Irani, Zahir & Brunel University (UK) & 1.53 & 4 \\
\hline 3 & French, Simon & University of Manchester (UK) & 1.50 & 2 \\
\hline 4 & van der Aalst, Wil M.P. & Eindhoven University of Technology (NL) & 1.17 & 2 \\
\hline 5 & Muylle, Steve & University of Ghent (BE) & 1.08 & 3 \\
\hline
\end{tabular}




\begin{tabular}{|c|c|c|c|c|}
\hline \multicolumn{5}{|c|}{ Region 3: Pacific Asia } \\
\hline Rank & Researcher & University & $\begin{array}{c}\text { Adjusted } \\
\text { Count }\end{array}$ & $\begin{array}{l}\text { Normal } \\
\text { Count }\end{array}$ \\
\hline 1 & Zhuge, Hai & Chinese Academy of Sciences (CN) & 4.00 & 4 \\
\hline 2 & Chiu, Chao-Min & National Central University (TW) & 2.83 & 4 \\
\hline 2 & Teo, Thompson S.H. & National University of Singapore (SG) & 2.83 & 5 \\
\hline 4 & Ngai, E.W.T. & Hong Kong Polytechnic University (HK) & 2.75 & 5 \\
\hline 5 & Wu, Jen-Her & National Sun Yat-Sen University (TW) & 2.37 & 6 \\
\hline 6 & Bose, Indranil & University of Hong Kong (HK) & 2.17 & 4 \\
\hline 7 & Yang, Christopher C. & Chinese University of Hong Kong (HK) & 2.08 & 5 \\
\hline 8 & Choe, Jong-Min & Kyungpook National University (KR) & 2.00 & 2 \\
\hline 8 & Choi, Dae-Young & Yuhan College (KR) & 2.00 & 2 \\
\hline 8 & Huang, Ming-Hui & National Taiwan University (TW) & 2.00 & 2 \\
\hline 8 & Shih, Hung-Pin & Hsuan Chuang University (TW) & 2.00 & 2 \\
\hline 8 & Wu, Ing-Long & National Chung Cheng University (TW) & 2.00 & 3 \\
\hline 13 & Cheung, Waiman & Chinese University of Hong Kong (HK) & 1.92 & 5 \\
\hline 13 & Chen, Yen-Liang & National Central University (TW) & 1.83 & 5 \\
\hline 13 & Wang, Eric T.G. & National Central University (TW) & 1.83 & 4 \\
\hline 13 & Wang, Yi-Shun & National Changhua University of Education (TW) & 1.83 & 3 \\
\hline 17 & Love, Peter E.D. & Edith Cowan University (AU) & 1.53 & 4 \\
\hline 18 & Chan, Samuel W.K. & Chinese University of Hong Kong (HK) & 1.50 & 2 \\
\hline 18 & Kwon, Oh Byung & Kyunghee University (KR) & 1.50 & 2 \\
\hline 18 & Lee, Jae Kyu & Korea Advanced Institute of Science and Technology (KR) & 1.50 & 3 \\
\hline 18 & Yen, Benjamin P. C. & University of Hong Kong (HK) & 1.50 & 2 \\
\hline 22 & Hung, Shin-Yuan & National Chung Cheng University (TW) & 1.45 & 3 \\
\hline 23 & Han, Ingoo & Korea Advanced Institute of Science and Technology (KR) & 1.33 & 3 \\
\hline 24 & Hu, Ya-Han & National Central University (TW) & 1.25 & 3 \\
\hline 24 & Wang, Huaiqing & City University of Hong Kong (HK) & 1.25 & 3 \\
\hline 26 & Kim, Myoung Ho & Korea Advanced Institute of Science and Technology (KR) & 1.17 & 3 \\
\hline 26 & Lai, Vincent S. & Chinese University of Hong Kong (HK) & 1.17 & 3 \\
\hline 26 & Lee, Sangjae & Sejong University (KR) & 1.17 & 3 \\
\hline 26 & Pan, Shan L. & National University of Singapore (SG) & 1.17 & 3 \\
\hline 30 & Hsu, Meng-Hsiang & National Kaohsiung First University of Science and Technology (TW) & 1.08 & 3 \\
\hline 30 & Wei, Chih-Ping & National Tsing Hua University (TW) & 1.08 & 3 \\
\hline
\end{tabular}




\section{About the Authors}

Shin-Yuan Hung is Professor and Chair of Department of Information Management at National Chung Cheng University in Taiwan. He was a visiting scholar of the MIS Department at the University of Arizona during summer 2007-spring 2008. Prior to the visit, he had been the Secretary General of the same university. Dr. Hung received his bachelor degree in Statistics from the National Chung Hsing University in Taiwan and his master and doctoral degrees in Information Systems from the National Sun Yat-sen University in Taiwan. His current research interests include decision support systems, knowledge management, electronic commerce, and data mining. $\mathrm{He}$ has published a number of papers in Decision Support Systems, Information \& Management, Electronic Commerce Research and Applications, Information Technology \& People, Communications of the AIS, Journal of Organizational Change Management, Government Information Quarterly, Computer Standard and Interfaces, Pacific Asian Journal of Association for Information Systems, Journal of Chinese Information Management, among others.
Wei-Hsi Hung is an Assistant Professor of Information Management at National Chung Cheng University, Taiwan. He received his Ph.D. and Master degree ( $1^{\text {st }}$ Class Hons) from the Department of Management Systems at the University of Waikato, New Zealand. His research interests are in the areas of IS alignment, organizational critical activities, e-commerce, interpretive case studies, and supply chain management.

Tsan-Ching Kang is a Ph.D. candidate of the Department of Information Management at National Chung Cheng University in Taiwan. He received his master degree from the same university. His research interests include group communication, virtual community, technology acceptance, and knowledge management.

King-Zoo Tang is a doctoral student of Information Management at National Chung Cheng University in Taiwan. He received his master degree from the same university. His research interests include decision support systems, knowledge management, and electronic commerce. He has published papers in Government Information Quarterly and Journal of International Technology and Information Management. 